\title{
APROXIMAÇÃO ENTRE A FILOSOFIA DE HUGH LACEY E O CAMPO EDUCACIONAL EM CIÊNCIA, TECNOLOGIA E SOCIEDADE
}

\author{
ANDIARA PEREIRA DOS SANTOS CARDOSO' * \\ https://orcid.org/ 0000-0001-5269-3441 \\ JOÃO JOSÉ CALUZI ** \\ https://orcid.org//0000-0002-6724-7484 \\ ROSEMAR AYRES DOS SANTOS" *** \\ https://orcid.org/0000-0002-1068-2872
}

RESUMO: Este artigo objetiva estabelecer um diálogo entre o campo educacional em Ciência, Tecnologia e Sociedade (CTS) e a filosofia de Hugh Lacey, que mostra o papel desempenhado pelos valores na pesquisa tecnocientífica atual, oportunizando um novo olhar para as interrelações CTS. Desse modo, inspirados na Análise Textual Discursiva, aproximamos as categorias de Lacey com o enfoque CTS, resultando nas seguintes aproximações: (1) a inteligibilidade dos valores possibilita i) discutir a complexidade das relações CTS e, desse modo, ii) superar crenças distorcidas; (2) o desenvolvimento autêntico proposto por Lacey se aproxima do Pensamento Latino Americano em CTS devido i) ao endosso à participação pública na escolha de estratégias e ii) à necessidade de se voltar para o contexto e as prioridades locais; (3) a epistemologia de Lacey pode contribuir para o autoconhecimento do professor, auxiliando-o a refletir e concretizar seus objetivos educacionais.

Palavras-chave: Educação CTS. Filosofia de Lacey. Formação de Professores.

\section{UN ACERCAMIENTO ENTRE LA FILOSOFÍA DE HUGH LACEY Y EL CAMPO EDUCATIVO EN CIENCIA, TECNOLOGÍA Y SOCIEDAD}

RESUMEN: Este artículo pretende establecer un diálogo entre el campo educativo en Ciencia, Tecnología y Sociedad (CTS) y la filosofía de Hugh Lacey, que muestra el papel que desempeñan los valores en la investigación tecnocientífica

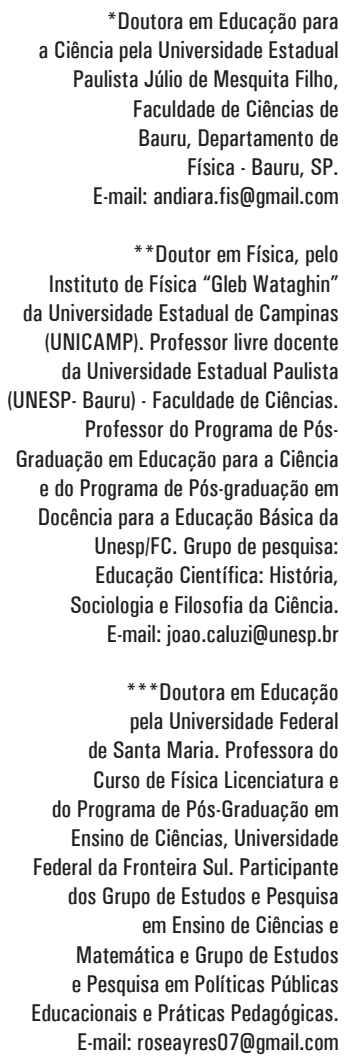

*Doutora em Educação para a Ciência pela Universidade Estadual Paulista Júlio de Mesquita Filho, Faculdade de Ciências de Bauru, Departamento de Física - Bauru, SP.

E-mail: andiara.fis@gmail.com

* * Doutor em Física, pelo Instituto de Física "Gleb Wataghin" da Universidade Estadual de Campinas (UNICAMP). Professor livre docente da Universidade Estadual Paulista (UNESP- Bauru) - Faculdade de Ciências. Professor do Programa de PósGraduação em Educação para a Ciência e do Programa de Pós-graduação em Docência para a Educação Básica da Unesp/FC. Grupo de pesquisa: Educação Científica: História, Sociologia e Filosofia da Ciência. E-mail: joao.caluzi@unesp.br

***Doutora em Educação pela Universidade Federal de Santa Maria. Professora do Curso de Física Licenciatura e do Programa de Pós-Graduação em Ensino de Ciências, Universidade Federal da Fronteira Sul. Participante dos Grupo de Estudos e Pesquisa em Ensino de Ciências e Matemática e Grupo de Estudos e Pesquisa em Políticas Públicas Educacionais e Práticas Pedagógicas. E-mail: roseayres07@gmail.com

I Universidade Estadual Paulista Júlio de Mesquita Filho, Faculdade de Ciências de Bauru, Departamento de Física, Bauru, SP - Brasil.

II Universidade Federal da Fronteira Sul, Cerro Largo, RS - Brasil 
actual, propiciando una nueva mirada a las interrelaciones CTS. Por lo tanto, inspirado el Análisis Textual Discursivo, acercamos las categorías de Lacey al enfoque CTS, lo que resultó las siguientes aproximaciones: (1) la inteligibilidad de valores permite i) discutir la complejidad de las relaciones CTS y, de ese modo, ii) superar creencias distorsionadas; (2) el desarrollo auténtico propuesto por Lacey se aproxima al Pensamiento Latinoamericano en CTS debido: i) al apoyo a la participación pública en la elección de estrategias, ii) a la necesidad de volverse al contexto y las prioridades locales; (3) la epistemología de Lacey puede contribuir al autoconocimiento del profesor, ayudándolo a reflejar y concretar sus objetivos educativos.

Palabras clave: Educación CTS. Filosofía de Lacey. Formación de Profesores.

\section{APPROXIMATION BETWEEN THE PHILOSOPHY OF HUGH LACEY AND THE EDUCATIONAL FIELD IN SCIENCE, TECHNOLOGY, AND SOCIETY}

ABSTRACT: This article aims to establish a dialogue between the educational field in Science, Technology, and Society (STS) and the philosophy of Hugh Lacey, which shows the role played by values in current technoscientific research, giving a new look to the STS mutual relationship. Thus, inspired by Discursive Textual Analysis, we approximate the categories of Lacey with the STS approach, wich resulted in the following approximations: (1) the intelligibility of the values makes it possible to i) discuss the complexity of the STS relations and, thus, ii ) allows overcoming distorted beliefs; (2) the authentic development proposed by Lacey approaches the Latin American Thought in STS due to (i) endorsing public participation in the choice of strategies and (ii) the need to turn to local context and priorities; (3) Lacey's epistemology can contribute to the self-knowledge of the teacher, helping him to reflect and achieve his educational goals.

Keywords: STS Education. Lacey's philosophy. Teacher training. 


\section{INTRODUÇÃO}

A importância dos valores nunca foi negada no âmbito educativo, como evidenciado na Lei de Diretrizes e Bases da Educação Nacional (LDB) e em novos documentos de cunho normativo, como a Base Nacional Comum Curricular (BNCC), bem como em diversas produções científicas. O cunho valorativo tem sido usado, principalmente, em discursos de pesquisadores e professores que tomam como meta a necessidade de abordar a complexa relação entre a Ciência, a Tecnologia e a Sociedade (CTS) visando a uma Educação para a Cidadania. Isso porque, são os valores atitudinais (CONRADO, NUNES-NETO; 2018) que movem para a ação almejada por quem vê a educação como objeto de transformação da realidade.

Nesse sentido, ao mapear 40 anos de produção científica no campo educacional em CTS, Pedretti e Nazir (2011) concluem que não há uma visão educativa única nessa linha de ação, categorizando a área em seis correntes não excludentes entre si e em constante mudança. Dentre elas, uma está comprometida em uma educação por valores de forma explícita, a chamada "centrada em valores." Essa corrente utiliza questões sociocientíficas como estratégia para ensinar que a Ciência e a Tecnologia (CT) estão centradas em valores; e, por meio dessa abordagem, valores globais, como a justiça, podem ser ensinados dentro de uma perspectiva de ensino que considera o desenvolvimento cognitivo e moral dos estudantes. De acordo com as autoras, os adeptos dessa corrente consideram que o enfoque CTS tem o impacto das decisões com respeito a CT na sociedade.

Outro desafio do campo está na formação dos professores, cujas concepções, advindas do modelo de formação disciplinar, têm causado visões distorcidas e ingênuas com respeito à atividade científica (AULER; BAZZO, 2001; AULER, 2002; CACHAPUZ et al., 2005). Além disso, as concepções dos estudantes sobre ciências podem ser fortemente influenciadas pelas concepções de seus professores (PRAIA; GIL-PEREZ; VILCHES, 2007), dificultando a participação social almejada no enfoque CTS.

Influenciados pela tecnociência, vemos que o controle e o domínio da natureza são valores amplamente difundidos em nossa sociedade, bem como o incentivo, cada vez maior, de inovações que sejam "úteis" ao homem, resquícios advindos do pensamento baconiano (LACEY, 2008a). Nesse contexto, há uma necessidade de revermos o papel dos valores dentro da educação científica; e por essa razão, nos aproximamos da filosofia de Hugh Lacey.

Hugh Lacey é um filósofo australiano radicado nos Estados Unidos, que lança mão da filosofia analítica da ciência para afirmar que valores podem ser inteligíveis; ele faz distinção entre os pessoais, sociais, religiosos, dentre outros; dos valores cognitivos como a adequação empírica, consistência teórica, simplicidade, fecundidade da teoria, poder explicativo para um conjunto de fenômenos etc. A partir desse momento, tal como Lacey coloca em suas obras, o termo valores será empregado para designar quaisquer tipos de valor (pessoal, religioso, ético, moral, etc.) que não sejam os cognitivos. Essa distinção é importante na epistemologia do autor, já que a distinção entre valores e valores cognitivos é o que torna possível uma correta avaliação de teorias científicas (LACEY, 2008; 2010).

Ao atribuir lugares próprios aos valores dentro da tecnociência, o autor 
se distancia da metafísica materialista, que afirma ser a ciência livre daqueles cujos ideais da neutralidade, imparcialidade e autonomia são satisfeitos. Contudo, diferente das bases do relativismo pós-moderno, em que há um predomínio da irracionalidade da ciência, o autor identifica que critérios de objetividade são efetivados sob a luz da avaliação cognitiva das teorias.

Do ponto de vista epistemológico, ao questionar se essa filosofia pode contribuir no campo educacional CTS, assumimos como hipótese que sua abordagem valorativa para explicar a tecnociência atual pode trazer reflexões para superação de lacunas existentes, como a dificuldade de articular a Ciência, a Tecnologia e a Sociedade e suas consequências para formação epistemológica dos professores. Para esse intento, tomamos a filosofia de Lacey como objeto de estudo; realizamos sua caracterização, que foi desdobrada em categorias; e as aproximamos das pesquisas recentes do campo educacional CTS do contexto brasileiro; tudo isso na tentativa de estabelecer associações entre elas. Obviamente, há muito a se fazer, contudo essa aproximação é uma primeira tentativa de mostrar as potencialidades da epistemologia valorativa para o âmbito educacional, o que tem importância para o nosso atual contexto político, histórico e social.

\section{ABORDAGEM TEÓRICO-METODOLÓGICA}

Para estabelecer associações é necessário fazer uma descrição do objeto para reconhecimento de suas categorias. Assim, a caracterização é uma etapa metodológica e não os resultados da pesquisa. Caracterizamos as obras de Lacey inspirados na Análise Textual discursiva (ATD), de Roque Morais, para, posteriormente, relacionar com o Campo Educacional em Ciência, Tecnologia e Sociedade.

Desse modo, tomamos como objeto as construções filosóficas de Lacey, que podem ser encontradas em livros e em diversos artigos. ${ }^{2}$ Para esse estudo, escolhemos as obras "Valores e Atividade Cientifica 1" e "Valores e atividade Cientifica 2", que é uma coletânea de artigos selecionados, dentre os quais, o mais antigo é de 1990. Além dessas obras, utilizamos o livro "Is Science value free? Values and scientific understanding" e dois artigos cujos títulos são: "Pluralismo metodológico, incomensurabilidade e o status científico do conhecimento tradicional" e "O modelo das interações entre as atividades cientificas e os valores", ambos publicados pela revista Scientice Studia, para mais detalhes consultar as referências deste artigo.

O último artigo tem coautoria de Pablo Rúben Mariconta, no qual se estabelece, entre outros números da mesma revista, o modelo de interação entre a ciência e valores, cuja principal diferença reside nos momentos lógicos estendidos para cinco momentos e não apenas três, como consta em outras produções do autor. No caso dos estudos feitos para esta análise, utilizamos os conceitos provenientes dos três momentos lógicos, pois para explicar a lógica dos valores, Lacey e Mariconda (2014) acabam por reduzi-los a três novamente (LACEY e MARICONDA, 2014, p. 650, fig. 3); por isso, nossa escolha não configura em simplificação para o intento deste trabalho.

Assim, categorizamos as principais ideias de Lacey de forma emergente, ${ }^{3}$ tal como é caracterizado a partir da Análise Textual Discursiva (ATD) (MORAES, 2003), ou seja, não havia categorias a priori. Após a desconstrução dos textos em 
unidades de sentido, utilizamos mapas mentais ${ }^{4}$ (BUZAN, 2009, 2013), com o fito de reorganizá-las e fazer com que emergissem por processos complementares de indução e dedução, embora nessa etapa a indução fosse mais presente. É necessário enfatizar que usamos a ATD não para dar novos significados aos textos de Lacey, mas para sistematizar e organizar o estudo realizado para caracterização. Por ser o autor dialético e seus textos estarem em uma coletânea de artigos, além de suas concepções sofrerem mudanças ao longo do tempo, sentimos a necessidade de um estudo mais sistematizado, por isso o uso de mapas mentais e de etapas da ATD.

Após as propriedades de pertinência, homogeneidade, exaustividade, saturação, amplitude e precisão serem satisfeitas (MORAES; GALIAZZI, 2006, 2007) com um mapa mental unificado (decorrente de vários mapas), foi possível compreender que existem conceitos principais e conceitos subordinados. Dentre esses, foi efetivada a separação pela perspectiva dos valores, como no Quadro 1:

Quadro 1. Organização dos conceitos principais (em negrito), conceitos secundários e valores

\begin{tabular}{|c|c|c|c|c|}
\hline \multirow[b]{2}{*}{$\begin{array}{l}\text { Categorias/ } \\
\text { Conceitos }\end{array}$} & \multicolumn{4}{|c|}{ BEM-ESTAR } \\
\hline & $\begin{array}{r}\text { Econô } \\
\text { Desenvolv }\end{array}$ & $\begin{array}{l}\text { (de poucos) } \\
\text { o Modernizador }\end{array}$ & $\begin{array}{r}\text { Soci } \\
\text { Desenvo }\end{array}$ & $\begin{array}{l}\text { ra todos) } \\
\text { nto autêntico }\end{array}$ \\
\hline \multirow{2}{*}{ Estratégia } & Materiali & D/reducionista & \multicolumn{2}{|c|}{ Multiplicidade de estratégias } \\
\hline & {$[X]$ valores } & [] v. cognitivos & {$[\mathrm{X}]$ valores } & [ ] v. cognitivos \\
\hline \multirow{2}{*}{$\begin{array}{l}\text { Entendimento/ } \\
\text { conhecimento } \\
\text { já avaliado de } \\
\text { acordo com a } \\
\text { imparcialidade }\end{array}$} & \multicolumn{2}{|c|}{ Moderno/extensivo } & \multicolumn{2}{|c|}{ Completo } \\
\hline & [ ] valores & {$[X]$ v. cognitivos } & [ ] valores & {$[X]$ v. cognitivos } \\
\hline \multirow{2}{*}{$\begin{array}{c}\text { Produto } \\
\text { Tecnocientífico }\end{array}$} & \multicolumn{2}{|c|}{ Alta Tecnologia } & \multicolumn{2}{|c|}{ Tecnologia Apropriada } \\
\hline & {$[\mathrm{X}]$ valores } & [] v. cognitivos & {$[\mathrm{X}]$ valores } & [] v. cognitivos \\
\hline
\end{tabular}

Fonte: (CARDOSO, 2017) a partir das obras de Lacey listadas acima.

No topo do Quadro 01 está o conceito de bem-estar social, que pode estar voltado tanto para o bem-estar amplo, como para o bem-estar de uma parcela mínima da sociedade. Lacey problematiza o conceito de bem-estar dentro do fenômeno tecnocientífico, analisando os valores dentro e fora desse fenômeno. Há uma relação de dependência entre a perspectiva de valor adotada (conjunto de valores) e o bem-estar ligado à concepção de desenvolvimento de uma sociedade (também pode ser uma comunidades específicas e dependentes do contexto).

Pela abordagem do artigo, colocamos o desenvolvimento social como categoria mais ampla, que pode ser avaliada pela perspectiva de valor adotada por uma sociedade, comunidade, país ou tradição, em que possuem três categorias principais: entendimento científico, estratégia e produto tecnocientífico. As categorias secundárias, também, subordinadas à perspectiva de valor adotada 
caracterizam os conceitos principais, como será mostrado na sessão dedicada à associação entre Lacey e a educação CTS.

À seguir, expressaremos, brevemente, os conceitos principais para compreensão da associação a ser realizada. Detalhes referentes à objetividade mantida pelas citações diretas podem ser encontradas de forma mais robusta em Cardoso (2017).

\subsection{ENTENDIMENTO CIENTÍFICO E O IDEAL DA IMPARCIALIDADE}

O entendimento científico está ligado a um objetivo e responde perguntas sobre o que é? por quê? esse objeto ou fenômeno é o que é; e como? ou seja, qual seria o inventário de suas possibilidades? Para obter entendimento científico de um objeto, ou um conjunto de fenômenos, é necessário compreender sua natureza em sua ordem subjacente, determinando suas propriedades, comportamentos e relações entre variáveis (ex: temperatura, pressão, tempo etc.), de forma a criar teorias científicas sustentadas por valores cognitivos manifestados em alto grau. Dentre eles: a adequação empírica, compatibilidade, consistência teórica, simplicidade, poder explicativo, fecundidade, etc. e que, para incluir qualquer valor cognitivo na lista, deve satisfazer as condições necessárias, de modo a:

[...] 1) explicar (mediante reconstrução racional) as escolhas de teoria efetivamente realizadas pela comunidade científica; e 2) que sua significação cognitiva ou racional seja bem sustentada [...] devem cumprir tantos encargos explicativos quanto normativos (LACEY, 2008a, p. 88).

Os valores cognitivos são manifestados de diferentes graus e em hierarquias distintas a depender da teoria. Contudo, a adequação empírica é considerada fundamental pela comunidade científica, que é um “ajuste" (“fit') entre a teoria e a observação. Essa teoria é corretamente avaliada se está de acordo com a imparcialidade.

Assim, para o autor, ela pressupõe que valores cognitivos sejam distintos de quaisquer outros tipos sejam eles sociais ou morais, ou seja, não há possibilidade de um e outro estarem lado a lado, no mesmo momento lógico. Para que uma teoria seja corretamente aceita, ela necessita ser avaliada sob a luz de juízos científicos bem fundamentados, em que eles são expressos em alto grau. Isso significa que "[...] servir a determinados valores ou ser consistente com as pressuposições de algum valor particular é irrelevante para a legítima aceitação de uma teoria" (LACEY, 2008a, p. 179-180).

Nessa perspectiva, a imparcialidade é um valor para a tradição científica moderna e, para o autor, é condição essencial para a correta avaliação de teorias, o que ele chama de avaliação cognitiva; uma teoria avaliada corretamente representa o entendimento de domínios específicos de fenômenos em que os valores cognitivos são manifestados em alto grau. Significa dizer, também, que essa teoria pode pertencer ao corpo de conhecimentos já estabelecidos e que não há razão, ao menos por ora, para duvidar que essa teoria seja refutada (LACEY; MARICONDA, 2014, p. 646).

Lacey apresenta, também, a avaliação não cognitiva, a qual entraria em etapa intermediária lógica, entre adoção de estratégias e a avaliação cognitiva, na qual interesses comerciais e motivações de ordem valorativa podem levar ao mercado antes que a pesquisa esteja completa com respeito aos riscos, perspectivas éticas, ou 
mesmo, uma teoria ser aceita devido ao prestigio do pesquisador (valores morais, éticos, políticos). Contudo, para o autor, a teoria só foi corretamente avaliada se submetida às avaliações em que somente valores cognitivos são utilizados. Isso implica que valores ${ }^{5}$ não têm papel legítimo ao lado deles se a imparcialidade for preservada. A distinção entre valores cognitivos e outros, como os sociais, é importante na epistemologia do autor (LACEY, 2010). ${ }^{6}$

Existe uma diferença entre ser e ter valor cognitivo ou ser e ter valor social: uma teoria científica que manifesta valores científicos em alto grau pode ter valor social; uma reivindicação social também pode ter valor cognitivo, com base em pesquisas empíricas e sistemáticas, por exemplo, das ciências sociais. Isso implica que o autor se compromete com a seguinte afirmação: “(...) existe um conjunto de valores cognitivos e 'é um objeto de valor social à luz de um conjunto de valores sociais' não é um deles” (LACEY, 2010, p. 272). O exemplo é o valor social da utilidade, próprio da influência Baconiana, do qual são selecionados apenas teorias que aumentem nossa capacidade de controlar objetos com vistas a serem úteis. Desse modo, quando forem corretamente aceitas, dentro da imparcialidade, tornam-se objeto de valor, enquanto outras linhas importantes de pesquisa são negligenciadas. O sucesso das aplicações tecnológicas decorrentes da teoria é uma explicação de que ela foi corretamente aceita e, portanto, válida para o domínio do fenômeno considerado.

\subsection{ESTRATÉGIA E A AUTONOMIA DA CIÊNCIA}

Produzir teorias de acordo com a imparcialidade não diz sobre a metodologia empregada; não explicita sobre que tipos de dados são importantes, quais seriam os procedimentos e em que categorias possibilitam a descrição desses dados. Dessa forma, Lacey emprega o conceito de estratégia como conceito norteador das práticas científicas. Se há uma estratégia, consequentemente, há perspectiva de valor e, portanto, a autonomia na tecnociência não é factível.

Podemos encontrar a autonomia preservada em algumas pesquisas básicas, entretanto, do ponto de vista da ciência aplicada, tecnociência, vemos que parte considerável avalia interesses não somente de instituições científicas e de interesse do pesquisador. Na tecnociência, os valores de instituições como as Força Armadas e as Indústrias de todos os ramos (com destaque nas indústrias farmacêuticas, cosméticas e alimentares) a autonomia não tem sido efetivada. Ela é trocada por esquemas ou conjuntos de valores que são materializados na estratégia adotada. O papel da estratégia é:

[...] em primeiro lugar, prescrever restrições aos tipos de teorias a serem consideradas e investigadas, e aos tipos de categorias que elas podem empregar e, assim, especificar os tipos de possibilidades que podem ser identificadas no curso da pesquisa e, em segundo lugar, selecionar os tipos relevantes de dados empíricos a serem obtidos e registrados, e os fenômenos e aspectos dos fenômenos a serem observados e tomados como objeto de experimentos (LACEY, 2010, p. 20).

Grande parte das pesquisas da ciência moderna utilizam estratégias que empregam descrições materialistas, em que os estudos dos fenômenos são isolados 
da vida prática e da natureza (LACEY, 2005, 2008a, 2010). O problema desse tipo de estratégia é que nem todas as possibilidades podem ser contempladas, já que são abstraídas às condições de vida humana e ambiente e vida prática. Desconsideram o contexto em que serão introduzidos os produtos advindos dessas pesquisas e quais seriam as verdadeiras necessidades locais. Por outro lado, estratégias sensíveis ao contexto, não redutíveis às abordagens descontextualizadas não são muito empregadas, mas podem ser uma solução de diminuição para o ideal da neutralidade cognitiva e promoção de bem-estar amplo de sociedades em desenvolvimento.

\section{Aplicação tecnocientífica e 0 ideal da neutralidade}

Para o cientificismo, ao ser a imparcialidade factível, a teoria aceita de acordo com valores cognitivos expressos em alto grau deve ser neutra; e todas as inovações da CT são aplicáveis em qualquer sociedade, podendo ser utilizadas tanto para o bem quanto para o "mal". O corpo de conhecimento científico produzido serve de forma equitativa nas sociedades democráticas, e também faz parte do patrimônio compartilhado da humanidade (LACEY e MARICONDA, 2014).

Assim, a neutralidade, do ponto de vista cognitivo, é uma consequência lógica da imparcialidade (LACEY, 2005, 2010; LACEY; MARICONDA, 2014); o que não é verdadeiro é a neutralidade do ponto de vista da aplicação (neutralidade aplicada) e, portanto, não pode ser preservada. O conhecimento, avaliado de acordo com a imparcialidade, foi anteriormente orientado por uma estratégia. Os produtos que advêm desse conhecimento estão voltados para os interesses da estratégia adotada: antes da avaliação já foram restringidos os tipos de teorias a serem pesquisadas e selecionado o corpo de dados empíricos e dos fenômenos a serem observados.

$\mathrm{Na}$ ciência moderna, a maior parte das pesquisas utilizam a abordagem descontextualizada em conjunto com o moderno esquema de valor do controle (valores do mercado, de capital e do progresso tecnológico), o que gera alta tecnologia (bightech) (LACEY, 2008a) ou tecnociência comercialmente orientada (LACEY; MARICONDA, 2014).

Para Lacey, mudando a perspectiva de valor ligadas ao controle para os valores ligados ao florescimento humano, em conjunto com a pluralidade de estratégias, é possível gerar tecnologia que seja apropriada ao contexto da comunidade, de forma a fomentar o bem-estar para maioria das pessoas de uma região. Para sociedades já consideradas desenvolvidas, essa perspectiva é de certa forma utópica, mas, para Lacey é possível a implementação em países em desenvolvimento como o Brasil ou, até mesmo, em algumas regiões.

Uma síntese de todos esses conceitos apresentados pode ser descrita por meio de três momentos lógicos principais: o da escolha da estratégia; da avaliação da pesquisa e da aplicação (Fig. 1). No primeiro, não necessariamente temporal, está a escolha da estratégia. Nele, há perspectiva de valor, portanto, a autonomia e a neutralidade não são factíveis. Do ponto de vista atual, as estratégias descontextualizadoras têm sido amplamente empregadas por valores ligados ao controle e à capacidade de gerar entendimento científico moderno. O segundo é a etapa de avaliar a teoria produzida, segundo a estratégia escolhida, contudo, para o autor, não há lugar para os valores provenientes dessa escolha ao lado dos valores 
cognitivos. Para avaliações corretas, sob a luz dos valores cognitivos disponíveis, a imparcialidade é preservada. O terceiro momento é o da aplicação. A seta que liga esse momento ao primeiro evidencia que os produtos advindos da pesquisa têm os mesmos valores da estratégia produzida, desse modo a neutralidade não pode ser preservada. Não queremos dizer com esse quadro que todas as pesquisas estão sob essa mesma lógica; somente aquelas aplicadas, ou seja, as de cunho tecnocientífico. As chamadas básicas não seguem essa lógica; contudo, para Lacey essas recebem a menor parte dos editais de financiamentos para pesquisas científicas.

Figura 1. Principais momentos lógicos da tecnociência atual. 0 primeiro momento é designado como M1, o segundo momento é M2 , o terceiro momento para M3 e Estratégias Materialistas/ Abordagem Descontextualizada é representado por EM/AB

$$
\text { M1 Escolha da estratégia } \longrightarrow \text { Não há autonomia }
$$<smiles>C1CC2CCC1C2</smiles>

Uso quase exclusivo da abordagem descontextualizada Valores subordinados ao controle Objetivo: Desenvolvimento modernizador

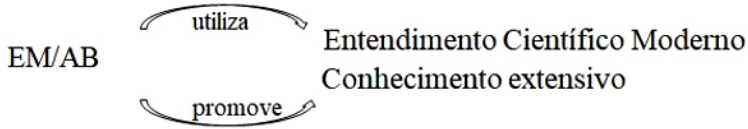

Teorias restringidas com dados empíricos selecionados

M2 Avaliação da teoria $\longrightarrow$ Imparcialidade<smiles>C1CC2CCC1C2</smiles>

M3 Aplicação do conhecimento

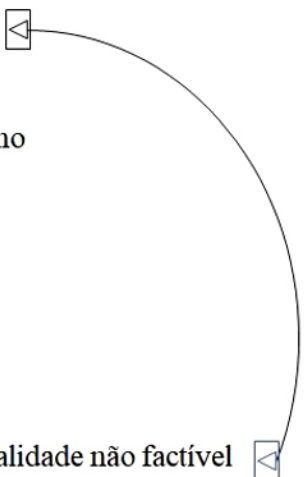

Fonte: CARDOSO (2017).

De posse dessas especificações referentes às categorias principais e, de certa forma, já introduzindo as secundárias, destinaremos a próxima seção ao detalhamento dos conceitos de desenvolvimento modernizador e autêntico, para estabelecer aproximações com o contexto educacional CTS. Na seção seguinte os conceitos secundários se tornarão mais presentes.

\section{APROXIMAC̣ÕES ENTRE A FILOSOFIA DE LACEY E A EDUCAÇÃO CTS}

De posse dessas categorias, foi possível associar alguns conceitos com o campo educacional em CTS. Para tanto, utilizamos os conceitos de desenvolvimento modernizador e o autêntico, que vamos detalhar nessa seção. O campo educacional em CTS tem diversas abordagens, não necessariamente excludentes entre si, com diferentes perspectivas pedagógicas e níveis de abrangência, como nos mostra Pedretti e Nazir (2011) no contexto mundial e Strieder (2012) no contexto brasileiro. A partir desses conceitos pudemos problematizar as relações de (1) a (3) a seguir 


\section{(1) A inteligibilidade dos valores possibilita i) discutir a complexidade das relações CTS e, desse modo, ii) permite superar crenças distorcidas;}

Queremos mostrar aqui como o conceito de desenvolvimento modernizador construído por Lacey pode contribuir para inter-relacionar as três dimensões Ciência, Tecnologia e Sociedade, por meio dos valores. Essas interrelações com abordagem valorativa auxiliam na superação de crenças advindas do conceito de desenvolvimento linear, impregnado na sociedade moderna e que professores e pesquisadores do movimento CTS, aplicados ao campo educacional, tentam superar em si mesmos e em seus estudantes.

O modelo de desenvolvimento linear pode ser descrito por meio da equação: + ciência $=+$ tecnologia $=+$ riqueza $=+$ bem-estar social. Em seu bojo está a filosofia da ciência, que se fundamenta no positivismo lógico e na sociologia funcionalista da ciência, por autores como o filósofo alemão Rudolf Carnap (1891 - 1970) e o sociólogo americano Robert Merton $(1910$ - 2003), respectivamente. Nessa perspectiva, ao se afastar de valores sociais, na busca pela neutralidade, é possível chegar à verdade pela racionalidade lógica aliada à experiência, sem ausência de condicionantes sociais, políticos, religiosos, ou mesmo, pressupostos pessoais de pesquisadores. Em termos de construções tecnológicas, só é possível haver eficácia técnica, possibilitando melhorias por meio da tecnologia, se sua autonomia é preservada.

Visões distorcidas, ou crenças com respeito à ciência e à tecnologia, têm sido problematizadas pela literatura (SOLOMON, 1995) e ainda constituem um campo de batalha para a promoção da autonomia e da participação pública (HURD, 1997). Essas crenças, fortemente arraigadas podem ser enfraquecidas ou eliminadas utilizando um ensino que mostre o lugar dos valores nas complexas relações CTS. Para tanto, sem a pretensão de listar todas as crenças, vamos problematizar algumas delas, utilizando as categorias de Lacey:

i) A ciência tem mais valor que a tecnologia;

ii) A tecnologia é mero subproduto da ciência;

iii) A tecnologia não interfere na prática científica;

iv) A supervalorização da ciência como o conhecimento mais importante que outros tipos de conhecimentos, como as artes, a filosofia, as ciências sociais e humanas;

v) Os dados científicos são supervalorizados;

vi) Quanto mais uma sociedade tem patentes advindas das práticas científicas, mais avançada ela é;

vii) A tecnologia é determinante para produzir riqueza e bem-estar para população (determinismo tecnológico de AULER (2002));

viii) Se existe algum mal-estar advindo da ciência, a responsabilidade é da 
tecnologia que foi utilizada para o "mal". Ainda que haja algum "mal", a ciência poderá reverter o quadro - perspectiva salvacionista da C e T (AULER, 2002);

ix) As decisões com respeito à CT devem estar apenas nas mãos de pessoas que compreendem e não nas mãos da população leiga, ou de especialistas de outras áreas - superioridade do modelo de decisões tecnocráticas (AULER, 2002).

Nessa perspectiva, consideramos importante notar que as crenças estão fundamentalmente relacionadas com a capacidade de agir (LACEY, 2008a) e, pela leitura do autor, julgamos também pela falta de ação. Silenciamentos que professores e pesquisadores têm buscado solucionar podem ser mitigados pela junção de dois processos: a eliminação de crenças que limitam a participação e a reestruturação da hierarquia de valores por meio de processos educacionais. Essa última alternativa não será tratada aqui. Com respeito a eliminação de crenças, faremos inferências sobre os itens de i a ix, partindo da concepção de desenvolvimento linear, contrapondo com o desenvolvimento modernizador de Lacey.

Essas crenças podem estar presentes na própria concepção do cientista que não reflete sobre suas práticas (LACEY, 2008a); no professorado de ciências que não possui posicionamento epistemológico consciente; nas pessoas que apenas recebem, ou consomem passivamente, os "resultados" do conhecimento tecnocientífico. A epistemologia de Lacey pode contribuir para desmistificar essas crenças com o conceito de desenvolvimento modernizador. Com essa nomenclatura, o autor problematiza o empreendimento científico atual, utilizando as categorias já nomeadas no Quadro 1.

O desenvolvimento modernizador é um conceito criado por Lacey para compreender o status quo do empreendimento tecnocientífico atual e suas consequências sociais. Ele está ligado à estrutura neoliberal, representado por países denominados "desenvolvidos", que impulsiona o crescimento econômico e a industrialização avançada, bem como a transferência de tecnologia moderna entre países. Esses estão silenciosamente comprometidos com o sofrimento de países em desenvolvimento (LACEY, 2008a).

No desenvolvimento modernizador, o conhecimento científico é altamente valorizado pelas possibilidades de controle da natureza e para produção de novos aparatos tecnológicos. Lacey nomeia de conhecimento extensivo, aquele que é proveniente do entendimento científico moderno, que informa o desenvolvimento modernizador. Ele é produzido por orientações provenientes de abordagens descontextualizadas, juntamente com valores provenientes do moderno esquema do valor de controle (MEVC), restringindo possibilidades materiais, que venham a produzir tecnologia de ponta ou alta tecnologia (bightech) com vistas a proporcionar o "bem-estar" social.

O MEVC pode ser entendido como um conjunto de valores das sociedades neoliberais, que visam o aumento dos lucros do comércio, do consumo, do individualismo, da propriedade privada, da competitividade, da utilidade etc.; juntamente com o controle da natureza, que é próprio do ser humano. A afinidade entre os valores do MEVC e as estratégias descontextualizadoras promove a capacidade de entendimento e intervenção na ordem subjacente da natureza. 
Ao eleger estratégias que abstraem o objeto ou fenômeno do mundo da vida e do contexto natural, tem-se o objetivo de que, após o controle, esses fenômenos saiam do laboratório e retornem para outros espaços como produtos de consumo que sejam "úteis". Desse modo, a tecnologia não pode ser vista como inferior à ciência, uma vez que, pelas razões explicitadas, a produção tecnológica é o objetivo último. É uma mobilização do conhecimento científico, com vistas à produção de aparatos e dispositivo tecnológicos para melhorar ou inovar produtos do consumo. Assim, podemos entender que não apenas o avanço tecnológico possibilita a produção de teorias científicas cada vez mais precisas, aumentando nossa capacidade de compreender a natureza subjacente (i); e, também, não pode ser considerada como mero produto da ciência (ii), já que a produção de inovações tecnológicas é meta de práticas científicas de controle. Assim, a tecnologia é tão valorizada quanto o conhecimento que a produz, e é necessária para o desenvolvimento de novas teorias científicas.

Se, com o auxílio de altas tecnologias, é possível produzir dados empíricos cada vez mais precisos, a crença de que ela não interfere nas práticas científicas (iii) não se sustenta. Para Lacey, a relação mútua entre a Ciência e a Tecnologia define a tecnociência, porque incorpora práticas de pesquisa dentro de abordagens descontextualizadas, em que se almejam aplicações inovadoras, o que "torna largamente arbitrária qualquer distinção entre as duas" (LACEY, 2008b, p. 306). Dentro dessa perspectiva, Acevedo et al. (2005) também considera que a tecnociência pode ser designada como complexo científico-tecnológico que é um conjunto de atividades geradoras de "Investigação, Desenvolvimento e Inovação $(\mathrm{I}+\mathrm{D}+\mathrm{I})$, nas quais a ciência e a tecnologia estão intensamente imbricadas e se reforçam mutuamente [...]" (ACEVEDO et al., p. 125, 2005, tradução nossa).

Pelo sucesso em produzir aparatos tecnológicos, que aumentem cada vez mais o nível de desenvolvimento mercadológico da sociedade neoliberal, pesquisas científicas do mundo natural têm sido mais valorizadas do que outros tipos de conhecimentos - como as artes, a religião, a filosofia, os saberes culturais, etc., que não utilizam a abordagem descontextualizada e que não estão vinculadas diretamente à "utilidade". Isso porque as pesquisas científicas produzem inovações que geram lucros e aumentam o poder de intervenção de sociedades consideradas desenvolvidas e de instituições militares. Com os valores neoliberais, o conhecimento científico descontextualizado é supervalorizado em comparação com outras frentes do saber (iv), o que sustenta o bem de uma elite política e econômica. Segundo, Bergandi (2014, p. 03) o sistema atual de uma democracia representativa levou à formação de uma elite politica que forma, com a elite econômica, uma classe única, político-econômica, que raramente defende os interesses da população, geralmente trabalham contra a preservação do ambiente e a proteção da biodiversidade. Mesmo que o item (iv) seja uma realidade em sociedades que visam o desenvolvimento modernizador, que produz entendimento moderno com vistas ao controle, essa crença ${ }^{7}$ não pode ser legítima. Como será problematizado na aproximação (2), é necessário que haja uma unidade entre os conhecimentos de naturezas diversas para produção de conhecimento completo e não do conhecimento extensivo. 
Em decorrência doitem (iv), a valorização da abordagem descontextualizada com MEVC pode gerar a ideia de uma verdade absoluta, restrita a determinado domínio de fenômenos, devido à supervalorização dos dados científicos (v), o que não é o objetivo da ciência. A ciência utiliza proposições baseadas em avaliações de alto valor cognitivo, dentro de certo domínio de fenômenos. No entanto, que para outros domínios ou outros contextos, o conceito de verdade científica pode não ser aplicada. Para exemplificar, vemos na mídia resultados científicos, comprovados por dados de pesquisa, que um alimento pode emagrecer. A consequência imediata é a grande procura e consumo exacerbado do alimento referido, sendo omitida, muitas vezes, a metodologia do estudo, ou seja, para qual amostra populacional houve emagrecimento pelo seu uso e quais foram as condições de contorno realizadas para a experimentação. Assim, o fato de a ciência ser bem-sucedida em informar a tecnologia, pode levar a uma imagem distorcida (CACHAPUZ, PRAIA, JORGE, 2002) que pode, em alguns casos, finalizar qualquer discussão pelo simples fato de dizer que foi provado cientificamente.

Outra crença, mais ligada a representantes de políticas públicas, é a de que quanto maior o número de patentes, mais avançado é um país (vi), espelhamento quase absoluto de agendas de pesquisa (AP) de países ditos desenvolvidos. A medida do desenvolvimento, nessa perspectiva, está ligada ao poder de desenvolvimento tecnocientífico, que é o objetivo do desenvolvimento modernizador. Para Lacey, ele se baseia na produção de altas tecnologias, informadas pelo conhecimento extensivo direcionado pela abordagem descontextualizada. O conhecimento extensivo é o produto da ciência moderna, que utiliza tecnologia de ponta para maior compreensão e apreensão da ordem subjacente da natureza, de forma a aumentar o controle e expandir para práticas além do laboratório. Dessa forma, a produção de patentes de países desenvolvidos se torna cada vez maior. Já, países em desenvolvimento, com vistas a buscar maior alcance internacional, acabam por entrar em disputas e corridas que, muitas vezes, são inalcançáveis por desconsiderarem sua história e seu contexto. Para Lacey, países que buscam um desenvolvimento modernizador, negam sua condição, deixando de lado suas prioridades. Por conseguinte, há uma negação da pobreza que aumenta indícios de mal-estar de sua população.

Desse modo, a crença problematizada no parágrafo anterior pode ser consequência da concepção de desenvolvimento linear de que quanto maior a tecnologia, mais bem-estar é gerado (vii). Para essa ideologia, a tecnologia é determinante para prosperidade de uma sociedade e não há como desenvolver sem a relação mútua e reforçadora entre a CT. A grande diferença entre a concepção de desenvolvimento linear e o conceito de desenvolvimento modernizador de Lacey reside no fato de que, no primeiro, a tecnologia é mera consequência da atividade científica e no último há uma estratégia, comprometida com o MEVC, que direciona pesquisas científicas com vistas a gerarem inovações tecnocientíficas, impulsionando o consumismo e realimentando o mercado. Assim, a forma como Lacey descreve o conceito de desenvolvimento modernizador auxilia a compreender a complexidade das relações entre CTS nas sociedades ocidentais, desmistificando crenças advindas do desenvolvimento linear (BAZZO, PEREIRA; 2008).

Uma semelhança entre o desenvolvimento modernizador e o linear é com relação à finalidade última de pesquisas científico-tecnológicas: o bem-estar 
social, o que, em ambos os casos, têm se concentrado para a minoria. A tese do determinismo tecnológico visa o bem-estar, produzindo riqueza e facilidades. Nesse sentido, se voltarmos nosso olhar para a história vemos que facilidades e ganhos, tanto de tempo como de recurso, podem ser atribuídos, em grande parte, aos avanços tecnocientíficos. Eles possibilitaram a construção da sociedade moderna, altamente tecnológica; entrementes, com esses avanços, vieram junto impactos indesejados na sociedade e no ambiente (VASCONSELOS, 1992; PRAIA, GIL-PEREZ, VILCHES, 2007; PEREIRA, 2012; BAZZO et al., 2003). Tanto a concepção de desenvolvimento linear quanto as instituições que se comprometem com desenvolvimento modernizador, há esperança que mesmo havendo problemas decorrentes dos avanços tecnocientíficos, novas pesquisas poderão mitigar, ou até mesmo eliminar, os impactos dessas inovações. Essa crença, que Auler (2002) chama de perspectiva salvacionista da ciência (viii), tem origem na metafísica do materialismo científico.

Desde os primórdios do movimento CTS (GARCIA, 1996), pesquisadores reivindicam a participação pública nas decisões sobre os impactos provenientes das inovações, apesar de uma participação pouco expressiva. Uma crença, que possivelmente limita o engajamento público, é conhecida como modelo de decisões tecnocratas (ix), problematizada por Auler (2001, 2002). A crença é de que a população não possui conhecimentos necessários para a compreensão adequada, portanto, não são capazes de avaliar e decidir. Notamos que na equação do desenvolvimento linear, ${ }^{8}$ a palavra social aparece por último; a sociedade é a maior beneficiada dos progressos científico-tecnológicos e cabe a ela apenas aproveitar os benefícios, ou ter a esperança que, caso ocorra malefícios, novos avanços irão "salvar" a população de possíveis riscos, ou diminuir os efeitos colaterais (perspectiva salvacionista já discutida anteriormente. Nesse ponto, com o conceito de desenvolvimento modernizador de Lacey é possível reverter essa concepção equivocada de que a sociedade é a maior beneficiada das inovações, porque, como já foi dito, o bem-estar para esse tipo de desenvolvimento está concentrado na minoria que não se beneficia do desenvolvimento linear.

Podemos observar que os valores, em seus lugares próprios, são como uma "liga" que torna inteligível a complexidade das relações entre CTS. Além disso, para perspectivas pós-modernas, que já concebiam a existência dos valores embora não conseguissem explicar o sucesso tecnológico, vemos que a objetividade pode ser factível, o que preenche lacunas para compreender as relações CTS no contexto atual.

Assim, é interessante perceber, também, os valores de Lacey quando vai além do poder explicativo da versão atual da ciência moderna que vivemos e propõe romper com o status quo. Ele aproveita a necessidade de controle inerente da nossa humanidade e mostra que, ao trocar o MEVC por valores ligados ao florescimento humano, podemos ir ao encontro de um desenvolvimento autêntico, direcionando o conhecimento tecnocientífico para a produção de bem-estar amplo. 


\section{(2) 0 desenvolvimento autêntico proposto por Lacey se aproxima do Pensamento Latino Americano em CTS (PLACTS) devido: í) ao endosso da participação pública na escolha de estratégias, ii) necessidade de se voltar para 0 contexto e as prioridades locais;}

Lacey usa o termo desenvolvimento autêntico, ${ }^{9}$ com o fito de sublinhar a necessidade de considerar estruturas econômicas e sociais que atendam as necessidades e interesses de um povo (LACEY, 2008); pode ser entendido como a medida do bem-estar da maioria das pessoas de uma dada localidade. Alguns valores importantes, que estão vinculados ao desenvolvimento autêntico, são a coletividade, a diversidade, o respeito ao bem comum, o bem-estar da maioria e preservação do ambiente e respeito à natureza. Ele avança no sentido oposto ao desenvolvimento modernizador porque está comprometido com outras estruturas de valores; podem até ter alguns valores idênticos, mas que diferem na hierarquia. Enquanto o Desenvolvimento Modernizador é estruturado pelo MEVC, o valor prioritário para o desenvolvimento autêntico é o florescimento humano, aqui entendido no sentido de gerar bem-estar humano. Para compreender melhor esse termo, Feyerabend (2006, p. 357) discute as virtudes básicas entre os gregos: coragem, justiça e sabedoria. Segundo ele, uma virtude pode transformar-se em vício; por exemplo, a coragem descontrolada torna-se loucura. Outro aspecto importante apresentado por ele é que as virtudes são aprendidas como aprendemos nosso idioma, ou seja, "vivendo em uma comunidade que as pratica". Assim, são as virtudes aprendidas na convivência, em uma sociedade ou comunidade. Essa conclusão vem da discussão sobre a virtude em Aristóteles (1987). Nesse texto, afirma que todo o trabalho visa ao bem, e a felicidade do homem é o mais alto dos bens. A felicidade é atingida quando a sociedade aprende, pela convivência, os hábitos bons. Ele conclui que as virtudes também são aprendidas do mesmo modo. Mas, o que é a virtude? Para Aristóteles (1987, p. 32) é "a disposição de caráter que o torna bom e que o faz desempenhar bem sua função." Podemos reescrever o termo "florescimento humano" como "situação de proposperidade humana". Um dos sinônimos de prosperidade é felicidade. Assim, podemos dizer que o florescimento humano é uma situação de felicidade. O desenvolvimento autêntico é aquele que conduz à felicidade e não à submissão a um sistema produtivo que oprime o ser humano, (SHIVA, 1993).

Assim, o florescimento humano no entendimento de Lacey possui profundas relações com o bem-estar humano. Essa perspectiva pode ser vista no livro "Valores e Atividade Científica 1", na página 183, porém fica mais claro no livro "Valores e Atividade Científica 2". Nesse último, vemos no Capítulo 3 a pergunta lançada pelo autor: "(...) como deve a ciência proceder de modo a promover o bem-estar humano? " (LACEY, 2010, p. 101); e cita autores que retomam essa pergunta, ora usando bemestar (KICHER, 1993), como Lacey (2001a), ora usando o termo "florescimento humano" (DUPRÉ, 1993; KITCHER, 1998). Um exemplo de como Lacey usa esses dois termos de forma a ter o mesmo significado é na seguinte passagem:

(...) que ela proporciona estruturas suficientes para permitir que todas as pessoas vivam normalmente de maneira a manifestar valores, que quando integrados em uma vida inteira, geram uma experiência de bem-estar (satisfação, florescimento). Esse ideal, por sua vez, precisa ser complementado por uma caracterização de bem-estar 
(florescimento) humano (uma concepção de natureza humana) e como ele se entrelaça com os ideais morais de X” (LACEY, 2010, p. 274).

Como no caso do desenvolvimento modernizador, Lacey também divide a atividade tecnocientífica que objetiva o bem-estar amplo em momentos não necessariamente temporais, sobretudo, lógicos. Um resumo das etapas da avaliação de teorias que estabelecem uma prática voltada para o desenvolvimento autêntico está disponibilizada na Figura 2.

Figura 2. A tecnociência a serviço do bem-estar amplo

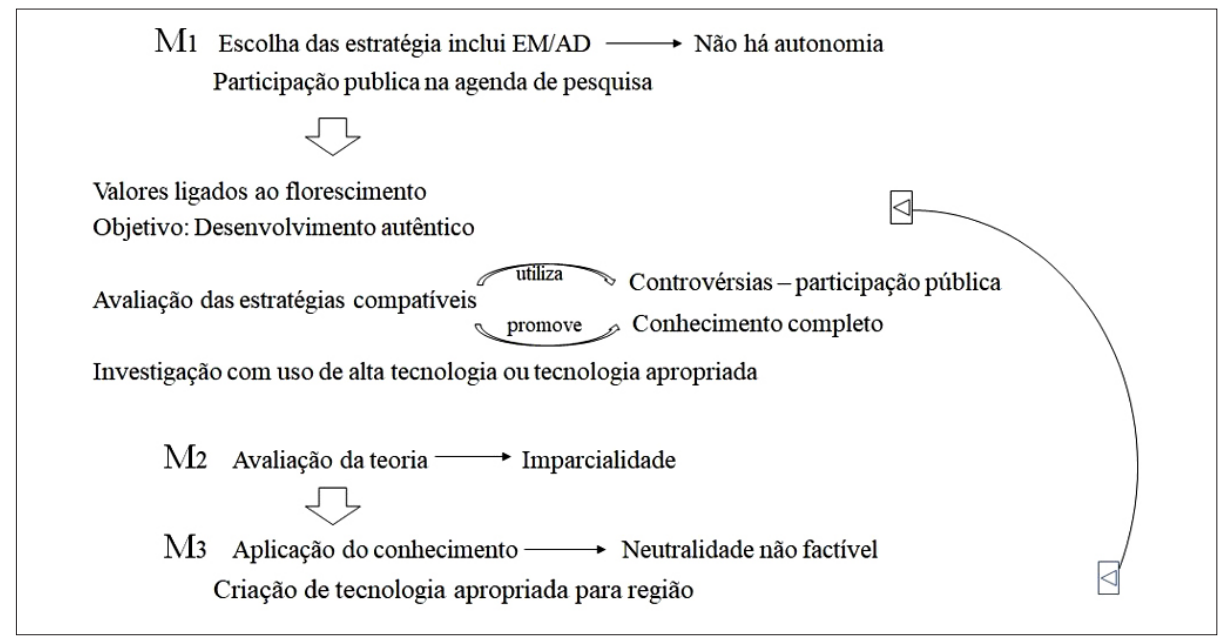

Fonte: Elaboração própria

Considerando um problema prioritário da região, o primeiro momento se dá na escolha das estratégias a serem utilizadas. Isso porque uma única estratégia não pode favorecer todas as possibilidades para a apreensão do fenômeno e sua relação com a vida prática e o ambiente. Além disso, o compromisso com a multiplicidade de estratégias (LACEY, 2012), o que inclui a abordagem descontextualizada, contribui para construção e criação de um conhecimento completo, advindo da compreensão de diversos olhares, complementando limitações que a estratégia única carrega. A escolha das estratégias é a primeira etapa lógica, não necessariamente temporal, em que são discutidas, por meio de participação democrática entre a comunidade e cientistas, a partir das mais diversas frentes do saber. Uma decorrência da diversidade de conhecimentos é uma aproximação da neutralidade cognitiva tão almejada na ciência (LACEY, 2010).

Por ser uma escolha que envolve valores que não são puramente cognitivos, a autonomia não pode ser preservada. Dessa forma, na ciência, ela não é factível tanto para pesquisas tecnocientíficas, ligadas ao MEVC, quanto para pesquisas voltadas para um problema prioritário de uma comunidade, ligadas ao desenvolvimento autêntico. Contudo, em ambos os casos, existe um comprometimento com valores. 
Ainda no primeiro momento lógico, problemas prioritários são levantados, discutidos e pesquisados, possibilitando escolhas pertinentes para montagem de uma AP própria da comunidade em questão. Nesse momento, a participação pública, anterior ao desenvolvimento da pesquisa, é fundamental. Para Lacey é importante que, no caso da pobreza, o pobre contribuía com a retificação de sua própria condição de sofrimento. Essa linha de pensamento pode promover a mudança da condição de vítimas para a construção do bem-estar de sua própria comunidade, o que legitima valores como a autonomia, cooperação, empoderamento e autoestima.

E, com respeito à participação pública na construção da AP, etapa anterior à produção do conhecimento, vemos uma aproximação com o Pensamento Latino Americano em CTS (PLACTS). Esse pensamento problematiza questões como a transferência de CT de países desenvolvidos para aqueles em desenvolvimento. Sugerindo, com isso, uma agenda científica própria, desvinculada da agenda dos denominados países de primeiro mundo e reivindicando, por conseguinte, que os investimentos com respeito à $\mathrm{CT}$ fossem concentrados para solucionar os problemas locais (DAGNINO, 2002; VACCAREZZA, 2011). O que se aproxima de Lacey, considerando que também reivindica a participação pública e a necessidade de construção de uma AP própria para uma comunidade ou país. E o Brasil, como outros países latino-americanos, se espelha na agenda de países desenvolvidos, incorporando como metas o que deveria ser somente uma inspiração ou modelo, descartando, muitas vezes, a autenticidade e o contexto que lhe é próprio.

Nesse sentido, para Lacey, após a adoção das estratégias, caso haja incompatibilidade entre elas, durante a investigação científica, a população deverá contribuir na decisão sobre qual conjunto de estratégias adotar. Só assim, após investigação empírica e sistemática, as sintetizações das possibilidades advindas das múltiplas estratégias adotadas produzem o conhecimento completo. Esse conhecimento é submetido à avaliação, na qual apenas valores cognitivos são considerados, sendo esse o segundo momento lógico de Lacey.

Assim, uma forma de reconhecer que esse conhecimento foi corretamente avaliado é na sua própria aplicação em tecnologia. Se a imparcialidade é preservada, o conhecimento completo informa o terceiro momento lógico, resultando em tecnologias apropriadas para as necessidades da região e que exprimem os mesmos valores das estratégias escolhidas democraticamente. O papel da tecnologia, nesse momento, é contribuir para o bem-estar da região considerada, porém, essa mesma tecnologia pode contribuir para a aquisição de outros saberes. Até mesmo tecnologias do tipo hightech podem ser utilizadas com vistas a contribuir nos estudos geradores de conhecimento completo, juntamente com outras tecnologias apropriadas. Lacey não exclui a abordagem descontextualizada, pois ela tem se mostrado eficaz para o entendimento da ordem subjacente da natureza.

Quanto ao movimento CTS no contexto educacional, pesquisas recentes mostram que a maior parte dos estudos brasileiros, no contexto educacional, têm privilegiado concepções provenientes do Hemisfério Norte sem contemplarem todas as potencialidades dessas concepções (ROSA e AULER, 2016; ROSO e AULER, 2016; SANTOS, 2016). Esses trabalhos, ao projetarem essas discussões em CTS para o campo educacional, enfatizam a participação pública, em grande parcela, relativa ao pós-produção, discorrendo sobre os impactos de produtos advindos da CT e deixando de lado, por vezes, discussões sobre a agenda de pesquisa. 
Por conseguinte, a concepção de desenvolvimento autêntico proposto por Lacey, além de reforçar a necessidade de participação pública no delineamento da AP, mostra a importância da multiplicidade de estratégias (LACEY, 2012) e a necessidade de desenvolver tecnologias apropriadas para resolver problemas sociais locais. Essas concepções se alinham com o PLACTS.

\section{(3) A epistemologia de Lacey pode contribuir para 0 autoconhecimento do professor, auxiliando-0 a refletir e concretizar seus objetivos educacionais.}

Discutimos, anteriormente, queháumalinhamento entre odesenvolvimento autêntico e os ideais de participação do PLACTS. Para que o desenvolvimento esteja alinhado com o bem-estar amplo, a educação científica em todos os níveis é um caminho promissor. É na educação que há possibilidades de mudanças e aquisição de valores. Notoriamente, é uma questão de políticas públicas, contudo, o professor que percebe suas práticas como importante ferramenta de mudança social pode auxiliar muito na construção do bem-estar amplo. Dessa forma, nosso intento é falar sobre algumas atividades para o professorado de ciências.

\section{Formação do Cientista e a Formação do Professor}

Roso e Auler (2016), entre outros autores, defendem a participação pública na construção da AP. Eles acreditam que, em termos educacionais, para que sejam formados para participação anterior à produção tecnocientífica, o currículo escolar deve ser reestruturado para atuar nessa mesma perspectiva. Sabendo que essa estruturação no currículo e nos objetivos educacionais necessita de mudanças, influenciando na postura do professor, defendemos que a teoria de Lacey pode contribuir com a sua formação epistemológica. Trata-se de uma abordagem atual e que levanta discussões sobre as principais abordagens filosóficas da ciência moderna, além de ser uma perspectiva engajada com o bem-estar social amplo.

Para o professor de ciências naturais é imprescindível conhecer a atividade do cientista (TEIXEIRA, 2003; MAMEDE, ZIMMERMANN, 2005; VIEIRA, MARTINS, 2005), o lugar que ele ocupa, o contexto em que está inserido para fornecer ferramentas para questionar o pesquisador. Inclusive, persuadi-lo, utilizando mecanismos conceituais e lógicos, para que parte de sua atividade esteja voltada ao bem-estar da comunidade em questão. Compreender o que o cientista pode ou não fazer é, também, uma forma de empoderamento para questionar sua prática em benefício coletivo.

Nesse sentido, Lacey não se debruça de forma específica para a formação do professor de ciências naturais; contudo, ele fornece elementos necessários para a formação do pesquisador engajado com o desenvolvimento autêntico. Ao invés de se deixar pressionar pelo número de publicações, ou mesmo se voltar a um projeto pelo alto financiamento, o cientista precisa conhecer os valores que estão subjacentes ao seu trabalho e se comprometer com os impactos que sua atividade pode produzir. Para tanto, o cientista deve ser formado para obter autoconsciência de sua prática, o que Lacey informa seis quesitos a seguir: 
1) Estudar o lugar da ciência na sociedade humana e na vida contemporânea; 2) estudar os fatores que influenciam a atividade científica, suas escolhas de direções para a pesquisa e a forma e composição de suas comunidades e instituições; 3) estudar a relação da ciência (a sua busca, o conhecimento por ela obtido e suas aplicações) com o bem-estar humano e avaliar o valor da ciência com relação a outros valores sociais e humanos significativos; 4) examinar criticamente a interação entre os fatores cognitivos e sociais na atividade científica e, particularmente, tornar-se atento aos mecanismos por meio dos quais os fatores sociais possam veladamente (e impropriamente) misturar-se a maioria dos fatores cognitivos na execução de juízos teóricos; 5) alcançar uma percepção do que pode e do que não pode ser adquirido a partir da ciência, e de que isso poderia assumir formas diferentes sob condições sociais diversas que expressassem diferentes valores; 6) empenhar-se numa avaliação crítica das visões concorrentes sobre essas questões (2008a, p.187 e 188).

Com os seis quesitos mencionados, o pesquisador deve compreender que sua atividade, na maioria das vezes, utiliza a abordagem descontextualizada, que já foi escolhida em momento lógico anterior, por valores neoliberais voltados ao mercado. Ou, ainda, empreendimentos de natureza militar, entre outros órgãos em que estão voltados ao benefício de uma parcela mínima da população. Com a autoconsciência de sua prática e valores ligados ao bem-estar amplo, o cientista terá o poder de avaliar sua atividade e escolher se engajar em pesquisas comprometidas com o desenvolvimento autêntico.

Para que o desenvolvimento de uma comunidade se torne autêntico deve haver parceria entre diversos cientistas, técnicos e a população em geral. Dessa forma, é papel do professor, na perspectiva CTS, educar para participação pública, e para tanto, os seis quesitos para a formação do cientista deverão ser problematizados na formação do professorado, fazendo as devidas adequações próprias da área.

Seria um retrocesso político, pedagógico e epistemológico considerar que a formação do cientista e do professor deva ser a mesma. São atividades com especificidades e escolhas formativas diferentes. Contudo, esses quesitos são de natureza epistemológica e, portanto, necessária na formação do professor. Além disso, do ponto de vista da atual versão da ciência moderna em que vivemos, os quesitos mencionados são, de certo modo, diferentes do que tem sido ensinado até então na formação epistemológica do professor. Mesmo considerados por nós de fundamental importância, essa formação está alicerçada em estudos provenientes, em sua maioria, de filosofias do século XX. Estudar a teoria de Lacey, em conjunto com outros filósofos da ciência, pode favorecer o posicionamento epistemológico que ajudará na autorreflexão e avaliação das suas práticas com respeito ao lugar dos valores na atividade científica atual.

\section{Multiplicidade de estratégias no ensino}

Enquanto professores da linha tradicional utilizam apenas a abordagem expositiva como método de ensino, o professor voltado para as relações CTS utiliza uma multiplicidade de estratégias, do ponto de vista da didática das ciências. 
Embora não exclua a abordagem expositiva, utilizando-a em contextos necessários e com autoconsciência de suas práticas. Ele emprega diversas metodologias em seu ensino (role-play, simuladores, júri simulado, temáticas, controvérsias etc.) e adentra em várias disciplinas para problematizar, com seus estudantes, um tema tecnocientífico ou um problema social que tem, em seu bojo, a tecnociência.

Ao olhar o conhecimento científico a ser ensinado na sala de aula, pode parecer que o conceito de multiplicidade de estratégias no contexto educacional, seja basicamente o mesmo de interdisciplinaridade, mas isso não é sempre verdadeiro. Um aparato científico pode ser discutido em termos da química, da física e matemática de forma interdisciplinar e estar comprometida com a mesma perspectiva de valor de abordagens descontextualizadas. Não quer dizer que não possa ser utilizada; contudo, deve-se estar atento a quais abordagens estamos utilizando, inclusive presentes nas ciências sociais e humanas, que sejam baseadas em estratégias cujos valores sejam incompatíveis com o florescimento humano.

Algumas pesquisas educacionais recentes em CTS utilizam temas controversos ou questões sociocientíficas (CONRADO et al., 2016; CONRADO, NUNES-NETO, EL-HANI, 2017; RATCLIFFE, GRACE 2003), juntamente com pesquisas com vistas a preparar o alunado para a argumentação (CONRADO et al. 2015) que envolvam as relações de aparatos tecnocientíficos, a vida prática e o ambiente, bem como estimular a autonomia para novas questões de forma a envolvê-los em situações de ensino que fomentem ações sociopolíticas (HODSON, 2018). O estímulo à pesquisa pode fazer com que os estudantes tragam para sala de aula também textos e materiais em que os valores possam ser problematizados; e essa discussão valorativa (SADLER; ZEIDLER, 2004) deve ser levada para sala de aula de forma a entender e, possivelmente, retificar os valores que realmente levarão para o bem-estar local.

Com respeito a essas estratégias educacionais, próprias do professorado que se alinha com abordagens CTS e que foram mencionadas no parágrafo anterior, não vamos entrar em detalhes, pois foge do escopo deste artigo, já que queremos dar uma caracterização geral para mostrar aproximações com Lacey e a abordagem CTS. Contudo, gostaríamos de fazer algumas considerações que importam para o intento do texto que entra em consideração sobre os termos "Temas Controversos" e "Questões Sociocientíficas". Esses termos têm sido empregados na literatura educacional em ciências naturais como sinônimas (SAUCEDO e PIETROCOLA, 2019; HODSON, 2018; LEVINSON e KATO, 2016). Inclusive em Hodson (2018) o autor mostra que essas controvérsias podem ser internas ou externas à ciência.

A controvérsia pode ser interna à ciência, isto é, a informação científica necessária para formular um juízo sobre ela é incompleta, insuficiente, inconclusiva ou extremamente complexa e difícil de interpretar, ou pode ser externa à ciência, ou seja, enraizada em preocupações, crenças, valores e sentimentos sociais, políticos, econômicos, culturais, religiosos, ambientais, estéticos e/ou ético-morais. A capacidade de resolver a controvérsia interna depende crucialmente dos conhecimentos e habilidades de leitura crítica dos estudantes sobre $\mathrm{NdC}$, como discutido acima; a capacidade e a vontade para resolver as controvérsias externas dependem de uma análise cuidadosa das emoções, dos sentimentos, e de questões ético-morais e/ou posição política. (HODSON, 2018, p. 39 e 40) 
Essa diferenciação é relevante para a aproximação que estamos fazendo, já que existe uma natureza epistemológica diferente entre as controvérsias internas e externas à ciência. Lacey, como visto ao longo desse artigo, indica importantes contribuições dos valores tanto em nível interno à ciência, com valores cognitivos, quanto em como outros valores (sociais, morais, éticos) têm lugar e influenciam na tecnociência. $\mathrm{O}$ autor aprofunda mais nos valores cognitivos que nos sociais, o que para professores e pesquisadores que buscam um desenvolvimento maior nos valores para a educação científica possa encontrar em Lacey uma limitação. Realmente, é uma limitação o aprofundamento dos valores éticos e morais quando em comparação com a sofisticação dada por Lacey, ao tratar os valores cognitivos; contudo, não é um ponto cego.

Tanto nas obras Valores e atividade científica 1 e 2 e novos artigos, que não entraram nessa pesquisa, como no título "Adoção de medidas de precaução diante dos riscos no uso das inovações tecnocientíficas” (LACEY, 2019). Mesmo tratando de forma geral não deixa de fornecer literatura pertinente para questões éticas (LACEY, 2010, 2014, 2019)

\section{Valores e a capacidade de agir}

A epistemologia de Lacey, tanto quanto o movimento CTS estão interessados na capacidade de ação e para tanto, não é somente ensinar sobre produtos científico-tecnológicos e estar atento para novas abordagens, além da descontextualizada. Desde cedo, professores engajados podem ensinar valores que impulsionem a ação. Para o autor a dimensão fundamental do bem-estar é a capacidade de agir ou não que está intimamente relacionada aos valores. Para esse autor os valores têm dimensão de crença e desejo e podem ser tratados com racionalidade, por meio de pesquisas. Assim, seja uma pessoa $\mathrm{X}$, que possui um valor v como um valor social $\Phi$. Ela sustenta esse valor se, e somente se:

(1) X deseja que v se manifeste em grau elevado em $\Phi$;

(2) X acredita que a manifestação em grau elevado de v em $\Phi$ é parcialmente constitutiva de um "bom" $\Phi$;

(3) X está comprometido ceteris paribus a agir para aumentar ou para manter o grau de manifestação de v em Ф. (LACEY, 2010, p. 271)

Por conseguinte, no campo educacional CTS, vemos um forte endossamento e trabalho em (1) e (2). Contudo, pouca expressividade de (3) faz com que enfraqueça o campo e, por essa razão, trazer a epistemologia de Lacey para esse contexto pode contribuir com a linha de pesquisa. Se valores são inteligíveis e estão intimamente relacionados à nossa maneira de agir, pesquisas educacionais podem voltar seus esforços para entender quais são aqueles existentes em uma dada região. Além de identificar qual sua hierarquia no quesito participação pública e, a partir daí, modificálos de acordo com o contexto educacional, como: fixar os valores e mudar a hierarquia, eliminar algum valor (por meio de crenças que foram problematizadas na primeira subseção) que impeça a ação ou adicionar valores por meio de uma educação valorativa que impulsiona a participação (problematizada na segunda subseção). 


\section{CONCLUSÃO}

O objetivo desse artigo foi mostrar as relações de associação entre a filosofia de Lacey e o campo educacional CTS, bem como dar indícios de possíveis contribuições. Essa associação foi possível colocando a epistemologia de Lacey como objeto de estudo, organizando suas ideias em categorias e, posteriormente, aproximando-as com pesquisas da área.

Por meio do conceito de desenvolvimento modernizador e o entendimento dos valores neoliberais que direcionam a tecnociência, percebemos que parcelas minoritárias da população têm desfrutado de bem-estar. Dada a complexidade das inter-relações CTS, essa abordagem valorativa pode auxiliar a superar crenças que distorcem o alcance da tecnociência, bem como velam atuações de diversas instituições comprometidas com essa abordagem. É bem sabido na área que essas crenças dificultam a participação pública; e, nesse sentido, por se tratar de uma filosofia que faz uma síntese de como a tecnociência se desenvolve, nesta atual versão da ciência moderna, a teoria de Lacey pode contribuir com a superação dessas crenças.

O conceito de desenvolvimento autêntico mostra quais são os valores da filosofia de Lacey, e tem se aproximado mais do PLACTS do que outras vertentes aplicadas ao campo educacional brasileiro, porque endossam a inclusão da população nas decisões que dizem respeito à tecnociência na construção da AP e à produção autêntica de CT e voltam a atenção para superação de problemas locais.

E, a compreensão das categorias de Lacey dentro do Ensino de Ciências Naturais não somente ajuda na superação de crenças, como pode ajudar o professor no autoconhecimento de suas próprias práticas educacionais. Reflexões concernentes aos valores podem auxiliar na clareza de desejos, na consciência de intenções e novas formulações de objetivos educacionais.

Defendemos com essas três aproximações que há um alinhamento entre os valores da epistemologia de Lacey com os pressupostos educacionais em CTS. Não detectamos qualquer indício de divergência de natureza valorativa entre a teoria e o contexto educacional em CTS. Contudo, enfatizamos que essa pesquisa é inicial e, portanto, não esgotamos todas as possibilidades de associações ou mesmo dissociações. Incitamos que mais pesquisas possam ser realizadas de forma a responder perguntas como: em uma região específica, os professores têm autoconsciência epistemológica de seus valores e dos seus objetivos educacionais? É possível construir uma hierarquia de valores de modo que possa ser problematizada na formação de professores? Quais práticas fariam cultivar novas crenças que não apenas incentivem a participação pública, mas, também, que auxiliem na formação de um grupo amplo de professores à frente das políticas públicas e reivindiquem sua autovalorização? 


\section{REFERÊNCIAS}

ACEVEDO, A. VÁZQUEZ, A.; MARTÍN, M.; OLIVA, J. M.; ACEVEDO, P.; PAIXÃO, M. F.; MANASSERO, M. A. Naturaleza de la ciência y educación científica para la participación ciudadana: Una revisión crítica. Revista Eureka sobre Enseñanza y Divulgación de las Ciências, v. 2, n. 2, pp. $121-140,2005$.

ARISTÓTELES. Ética a Nicômaco. São Paulo: Nova Cultural, 1987. (Os Pensadores).

AULER, D.; BAZZO, W. Reflexões para a implementação do movimento campo CTS no contexto educacional brasileiro. Ciência \& Educação, v.7, n.1, p.1-13, 2001.

AULER, D. Interações entre Ciência, Tecnologia e Sociedade no contexto da formação de professores de ciências. 2002. 257f. Tese (Doutorado em Educação) Centro de ciências Naturais. Florianópolis. 2002.

BAZZO, W,; LISINGEM, I.; PEREIRA, L.T.V. Introdução aos estudos CTS (Ciência, Tecnologia e Sociedade). Organização dos Estados Ibero-americanos (OEI). Madri - Espanha 2003.

BAZZO, W.; PEREIRA, L. O que é CTS, afinal, na Educação Tecnológica? Revista Tecnologia e Cultura - Rio de Janeiro - ano 10, n. 13, p. 46-56, dez. 2008.

BERGANDI, D. Environnement, éthique et politique: les limites d'une démocratie inaboutie et leurs consequences néfastes sur la protection de la nature. Éthique publique, v. 16, n. 1, 2014. DOI 10.4000/ethiquepublique.1364. Disponível em: http://ethiquepublique.revues.org/1364. Acessado em: 03 jun. 2020.

BUZAN, T. Mind Map Handbook: The ultimate thinking tool. Thorson. 2013.

BUZAN, T. Mapas Mentais: Métodos criativos para estimular o raciocínio e utilizar ao máximo o potencial do seu cérebro. Sextante, Rio de Janeiro, RJ, 2009

CACHAPUZ, A.; GIL-PERES, D.; CARVALHO, A. M. P.; PRAIA, J.; VILCHES, A. A necessária renovação do Ensino das Ciências. Editora Cortez. São Paulo, 2005.

CACHAPUZ, A., PRAIA, J.; JORGE, M. Ciência, Educação em Ciência, Ensino de Ciência. Lisboa: Ministério da Educação. 2002.

CARDOSO, A. P. S. Contribuições da epistemologia de Hugh Lacey para Educação CTS: o contexto da nanotecnologia. 2017. 253f. Tese (Doutorado em Educação para Ciência), Faculdade de Ciências, UNESP, Bauru.

CEREZO, J. A. L. Ciencia, Tecnología y Sociedad: el estado de la cuestión en Europa y Estados Unidos. Revista Iberoamericana de Educación, n.18, pp. 41- 68. 1998.

CONRADO, D. M.; NUNES-NETO, N. Questões sociocientíficas e dimensões conceituais, procedimentais e atitudinais dos conteúdos no ensino de ciências. p. 77 a 118 In: CONRADO, D. M.; NUNES-NETO, N (org.) Questões Sociocientíficas: fundamentos, propostas de ensino e perspectivas para ações sociopolíticas. Editora Universidade Federal da Bahia (EDUFBA). Salvador (BA). 570p. 2018.

CONRADO, D. M.; NUNES-NETO, N; EL-HANI, C. Uma análise de arcabouços teóricos sobre questões sociocientíficas no ensino de ciências. In: XI Encontro Nacional de Pesquisa em Educação em Ciências - XI ENPEC Atas... Florianópolis, SC - 3 a 6 de julho de 2017 . 
CONRADO, D. M.; NUNES-NETO, N; EL-HANI, C. Argumentação sobre problemas socioambientais no ensino de biologia. Educação em Revista, 31, 329-357, 2015.

CONRADO, D. M.; NUNES-NETO, N; VIANA, B. F.; SCHNADELBACH, , A. S.; EL-HANI, C. Ensino de biologia a partir de questões sociocientíficas: uma experiência com ingressantes em curso de licenciatura. Indagatio Didactica, vol. 8(1), p. 1132- 47, julho 2016.

DAGNINO, R. Enfoques sobre a relação Ciência, Tecnologia e Sociedade: Neutralidade e Determinismo. In: Organização dos Estados Ibero-americanos para a Educação, a ciência e a cultura. Sala de Lectura CTS+I de la OEI. 2002.

FABIÁN, R. Comentarios criticos a las teorías de desarrollo dominantes: hacia otro concepto del desarrollo de las comunidades. Realidad (El Salvador). 4, p, 713-61, 1991

FEYERABEND, P. A conquista da abundância. São Leopoldo/RS: Editora UNISINOS, 2006, 374 p.

GARCÍA, M. I. G.; CEREZO, J. A. L.; LÓPEZ, J. L. L. Ciencia, Tecnologia Y Sociedad : una introducción al estudio social de la Ciência y la tecnología. Madrid: Tecnos, 1996.

LACEY, H. Is Science value-free? Values and scientific understanding. Routledge. London and New York. 2005.

LACEY, H. Valores e atividade Científica 1. Associação Filosófica Scientiae Studia. São Paulo. 2008a.

LACEY, H. Ciência, respeito à natureza e bem-estar humano. Scientiae Studia. São Paulo. V.6, n.3 pp. 297-327, 2008b.

LACEY, H. Valores e atividade científica 2. Editora 34. São Paulo. 2010.

LACEY, H. Pluralismo metodológico, incomensurabilidade e o status científico do conhecimento tradicional. Scientiæ Studia, São Paulo, v. 10, n. 3, p. 425-53, 2012.

LACEY, H; MARICONDA, P. R. O modelo das interações entre as atividades científicas e os valores. Scientiæ Studia, São Paulo, v. 12, n. 4, p. 643-68. 2014.

LACEY, H. Qué tipo de ciencia le sirve al desarrollo auténtico? Realidad, 8, p. 369-82, 1994.

LACEY, H. Distinguishing between cognitive and social values. In Kevin Elliott \& Daniel Steel (eds.), Current Controversies of Values in Science, pp. 15-30. New York: Routledge, 2017.

LACEY, H. Appropriate roles for ethical and social values in scientific activities. Essay Review of Kevin C. Elliott, A Tapestry of Values: An introduction to values in science. Metascience 27(1), 2018: 69-73.

LACEY, H. Roles for values in scientific activities. Axiomathes 28(6), 2019: 603-618.

LACEY, H. Adoção de medidas de precaução diante dos riscos no uso das inovações tecnocientíficas. Estud. av., São Paulo , v. 33, n. 95, p. 245-258, jan. 2019. Disponível em:<http://www.scielo.br/ scielo.php?script $=$ sci_arttext\&pid $=$ S0103-40142019000100245\&lng $=\mathrm{pt \& nrm}=\mathrm{iso}>$. Acessos em: 06 jun. 2020. https://doi.org/10.1590/s0103-4014.2019.3395.0016.

MAMEDE, M.; ZIMMERMANN, E. Letramento científico e cts na formação de professores para o ensino de ciências. Enseñanza de las Ciencias. Número Extra. VII Congreso. 2005

MORAES, R.; GALIAZZI, M. C. Análise textual discursiva: processo reconstrutivo de múltiplas faces. Ciência \& Educação, v. 12, n. 1, p. 117-128, 2006. 
MORAES, R.; GALIAZZI, M. C. Análise textual discursiva. Ed. Unijuí, 2007.

MORAES, R. Uma tempestade de luz: a compreensão possibilitada pela análise textual discursiva. Ciência \& Educação, v. 9, n. 2, p. 191-211, 2003.

PEDRETTI, E.; NAZIR, J. Currents in STSE Education: Mapping a complex field, 40 years on. Science Education. p. 601-626, 2011.

PEREIRA, E. M. Rachel Carson, Ciência e Coragem. Programa de pós-graduação em história da Universidade Federal do Rio Grande do Sul Ciência. Ciência Hoje. 2012 .

PRAIA, J.; GIL-PEREZ, D.; VILCHES, A. O papel da natureza da ciência na educação para a cidadania. Ciência \& Educação. v. 13, n. 2, p. 141- 156, 2007.

RATCLIFFE, M.; GRACE, M. Science education for citizenship: teaching socioscientific issues. Maidenhead: Open University Press, 2003.

ROSA, S. E.; AULER, D. Não Neutralidade da Ciência-Tecnologia: Problematizando Silenciamentos em Práticas Educativas CTS. Alexandria, v. 9, n. 2, p. 203-231, 2016.

ROSO, C. C.; AULER, D. A participação na construção do currículo: práticas educativas vinculadas ao movimento campo CTS. Ciência \& Educação, Bauru, v. 22, n. 2, p. 371-389, 2016.

SADLER, T.; ZEIDLER, D. The morality of socioscientific issues: Construal and resolution of genetic engineering dilemmas. Science Education, 88 (1), pp. 4 - 272004

SANTOS, R. A. Busca de uma participação social para além da avaliação de impactos da CiênciaTecnologia na sociedade: Sinalizações de práticas educativas CTS. 2016. 203p. TESE (Doutorado em Educação), Centro de Educação, Universidade Federal de Santa Maria, Santa Maria, RS, 2016.

SAUCEDO, K. R.; PIETROCOLA, M. Características de pesquisas nacionais e internacionais sobre temas controversos na Educação Científica. Ciênc. Educ., Bauru, v. 25, n. 1, p. 215-233, 2019

SHIVA, V. The violence of the green Revolution. Nova Jersey (USA): Zed Books; Penany (Malásia): Third World Network, 1993.

SOLOMON, J. The dilemma of Science, Technology and Society Education. In: FENSHAN, P. (ed.). Development and dilemmas in Science Education. The Falmer Press. (Contemporary Analysis in Education Series). London; New York; Philadelphia. pp.266-281. 1995.

TEIXEIRA, P. M. A Educação Científica sob a perspectiva da Pedagogia HistóricoCrítica e do movimento C.T.S. no Ensino de Ciências. Ciência \& Educação, v. 9, n. 2, p. 177-190, 2003.

VACCAREZZA, Leonardo Silva. Ciencia, Tecnología y Sociedad: el estado de la cuestión en América Latina. Ciência \& Tecnologia Social: A construção crítica da tecnologia pelos atores sociais. v. 1, n.1, 2011.

VASCONCELOS, Laécia Abreu. Algumas características da readaptação de sobreviventes da bomba atômica em Hiroshima. Psicologia: Teorias e Pesquisa. Brasília. n. 1; vol.8; pp. 113- 122. 1992.

\section{NOTAS}

1 Uma análise de todas as vertentes do artigo citado e onde o leitor pode encontrar outras traduções para as abordagens mencionadas ver Conrado e Nunes-Neto (2018). 
2 Para verificar a produção bibliográfica do autor conferir em http://www.swarthmore.edu/ Humanities/hlacey1/publications.html. Acessado em: 20 fev. 2019.

3 Como não teve categorias a priori, pelo fato de que queríamos caracterizar as obras do autor, colocamos as categorias classificadas como emergentes da análise, já que utilizamos os próprios conceitos nomeados pelo autor. Por isso colocamos no Quadro 1 "categorias/conceitos". Existem outras possibilidades de categorizar as obras de Lacey, como a própria metodologia da ATD permite. O estudo que fizemos inspirados na ATD e o enfoque que pretendíamos, chegaram nessas categorias.

4 Por utilizar os mapas mentais, dizemos que a metodologia foi "inspirada" na ATD para o estudo que visava caracterizar as obras do autor. Isso para, posteriormente, confrontar com o campo educacional em CTS e tecer algumas de suas potencialidades nesse campo

5 Ver definições na introdução.

6 Ver nessa referência o capítulo 11. A distinção entre valores cognitivos e valores sociais é objeto de controvérsia entre filósofos da ciência e o referido autor aborda mais claramente essa distinção em Lacey $(2017,2018,2019)$.

7 Estamos chamando de crenças o que Auler (2002), dentre outros, chamam de mitos, porém, a problematização do item (iv) mostra que há diferenças do ponto de vista valorativo. Isso porque, a crença é uma dimensão dos valores. Para Lacey, elas têm dimensões tanto de crença quanto de desejo e podem ser observados por meio de fatos, de forma que são inteligíveis. No caso da primeira, ela é material, corresponde à realidade, ao contrário do mito. Mesmo já estando materializada, não significa que essa crença deveria existir. Ela pode ser mitigada ou eliminada na medida que valores mais igualitários, perante a diversidade de conhecimentos, fossem incorporados na educação científica, de forma a mudar as crenças e, por conseguinte, transformar a realidade.

8 O desenvolvimento científico (DC) gera desenvolvimento tecnológico (DT), que, por sua vez, gera desenvolvimento econômico (DE), o qual, necessariamente, resultará em desenvolvimento social (DS), ou seja, DC+DT+DE=DS (GARCIA, CEREZO e LÓPEZ, 1996).

9 Lacey toma emprestado, provisoriamente, o termo "autêntico" (LACEY, 2008, p. 190 e 200, notas de rodapé 2 e 12) de discussões latino-americanas e remete a referências tais como Fabián (1991) e Lacey (1994).

\section{Submetido em 03/03/2019}

Aprovado em 15/06/2020

\section{Contato:}

Andiara Pereira dos Santos Cardoso

Endereço para correspondência:

Rua T-37, n. 4029, apto 2003 - Setor Bueno. Edifício Olympus | Torre Kastória

CEP 74.230-025 - Goiânia, GO - Brasil 